one hundred less than in the victims of the Yusho accident and in the Seveso residents (referring to the mean value in the most contaminated zone), but would be similar to the two- to threefold increase in PCB and dioxin body burden of subjects affected in the $1980 \mathrm{~s}^{5}$ or of those regularly eating contaminated seafood ${ }^{6}$.

A. Bernard ${ }^{\star}$, C. Hermans ${ }^{\star}$, F. Broeckaert ${ }^{\star}$, G. De Poorter $\dagger$, A. De Cock $\dagger$, G. Houins $\dagger$

* Unit of Toxicology, Catholic University of Louvain, 30.54 Clos Chapelle-aux-Champs,

1200 Brussels, Belgium

\title{
Reproductive biology
}

\section{Pheromones and regulation of ovulation}

There is controversy surrounding the issue of whether there is menstrual synchrony in women who live together ${ }^{1-4}$, particularly in the case of the coupled-oscillator model developed $^{5}$ to explain similar data from rats. Stern and McClintock ${ }^{6}$ have proposed that the rat model applies to women, with the effect being mediated by two opposing axillary 'pheromones' that could affect major reproductive events and have potential for "either contraception or treatment of infertility".

This claim ${ }^{6}$ is based on data derived from four cycles from each of 20 subjects treated with axillary compounds to change the cycle length from that of each subject's baseline cycle. Subjects' upper lips were wiped daily with pads worn in the axillae of donors in follicular or ovulatory phases of their cycles. The cycles of subjects wiped with follicular pads appeared to be shortened by 1-14 days, whereas cycles of those wiped with ovulatory pads were longer by 1-12 days. One-third of cycles did not change or changed in the opposite direction.

My main criticism of the study is the use of the value of the single first cycles, receiving carrier-only treatment, to derive the data analysed. Such single observations have no within-subject variance and the irregular statistical manoeuvre of converting all 20 observations to zero masks any between-subject variance and provides an illusory zero baseline with indeterminate confidence limits. Carrier-only treatments should have been distributed throughout this long experiment to give a balanced crossover design with three treatments (carrier, follicular and ovulatory) and two or more complete replications to confer confidence limits to the baseline observations, thus making comparisons valid.

Each group has an apparent outlier favourable to the model: one of -14 comprises $25 \%$ of the total shortening, whereas

e-mail:bernard@toxi.ucl.ac.be $\dagger$ Belgian Federal Ministery of Agriculture, WTC3 Boulevard S. Bolivar 30, 1000 Brussels, Belgium

1. Gilbertson, M., Kubiak, T., Ludwig, J. \& Fox, G. J. Toxicol. Environ. Health 33, 455-520 (1991).

2. Masuda, Y. in Dioxins and Health Vol. 1 (ed. Schecter, A.) 633-659 (Plenum, New York, 1994).

3. Kohanawa, M., Shoya, S., Yonemura, T., Nishimura, K. \& Tsushio, Y. Natl Inst. Anim. Health Q. Tokyo 9, 220-228 (1969).

4. Harris, J. R. \& Rose, L. J. Am. Vet. Med. Assoc. 161, 1584-1586 (1972).

5. Papke, O. Environ. Health Perspect. 106 (suppl. 2), 723-731 (1998).

6. Asplund, L. et al. Arch. Environ. Health 49, 477-486 (1994).

that of +12 makes up $22 \%$ of the increase. Excluding these two outliers would abolish the claim of significance.

Reference to the first cycle throughout the long experiment may have introduced biases because of environmental, physiological and social drifts. McClintock ${ }^{1}$ reported that women "who estimated seeing males less than three times per week" had cycles 1.5 days shorter than those who spent more time with males. Others claim that cycles are affected by sexual activity or the phase of the moon ${ }^{7,8}$.

I am not convinced of the validity of the coupled-oscillator model derived from rat studies ${ }^{5}$. I also question the "definitive evidence" that pheromones regulate human ovarian function because, if these exist, their characterization will require large, carefully designed experiments, a controlled social and physical environment, and a clearly defined endpoint measured in hours.

\section{Wes Whitten}

Department of Molecular Medicine,

Australian National University, PO Box 334,

Canberra City, ACT 2601, Australia

e-mail:whitten@istar.ca

1. McClintock, M. K. Nature 291, 244-245 (1971).

2. Trevathan, W. R., Burleson, M. H. \& Gregory, W. L.

Psychoneuroendocrinology 18, 425-435 (1993).

3. Wilson, H. C. Psychoneuroendocrinology 17, 565-591 (1992).

4. Strassmann, B. I. Curr. Anthropol. 38, 123-129 (1997).

5. Schank, J. \& McClintock, M. K. J. Theor. Biol. 157, 317-362 (1992).

6. Stern, K. \& McClintock, M. K. Nature 392, 177-179 (1998).

7. Cutler, W. B., Garcia, C. R. \& Kreiger, A. R.

Psychoneuroendocrinology 4, 297-309 (1979).

8. Cutler, W. B. Am. J. Obstet. Gynecol. 137, 834-839 (1980).

McClintock replies - We first reported menstrual synchrony almost three decades ago, and it has since been verified repeatedly. But synchrony does not always occur, and the circumstances in which it does not occur tell us a great deal about the social and physical conditions required ${ }^{1,2}$. Menstrual synchrony is but one manifestation of a more fundamental mechanism, the chemosensory regulation of ovulation, which occurs in other species not only as synchrony, but also as asynchrony, extreme cycle regularity, changes in the timing of puberty, birth cycles and reproductive ageing ${ }^{1,2}$.
One of the studies ${ }^{3}$ cited by Whitten to support his statement that synchrony is still controversial describes a non-random relationship between the cycles of lesbians living together, albeit not in synchrony. It is therefore consistent with our idea that ovarianmodulating chemosignals provide a basic mechanism that also gives rise to diverse forms of social regulation of ovulation.

Whitten implies that our data were poorly controlled, skewed and selected, but his criticisms do not hold with a careful reading of the experimental details ${ }^{4}$. The main criticism is based on a misreading of our procedure for within-experimental-subjects control. Each woman in the group was studied for five, not four, cycles and was exposed first to the carrier and then to follicular and ovulatory axillary compounds (in balanced randomly assigned order). We did not ignore the environmental, physiological and social factors that cause variation between women in the length of the menstrual cycle to be greater than the variation within women. Our within-subjects design controlled for this, and included the standard normalization procedure of expressing data as a change in cycle length from the baseline cycle preceding each condition. Statistical analyses were done only on these four change-scores (the baseline cycle lengths, all standardized to zero, were only depicted graphically).

Two other analyses also demonstrated the effect of human axillary compounds on ovarian function. A second control group of women who received only the carrier (frozen and thawed undercast pads with a few drops of alcohol) were significantly different from the experimental group, who also received both types of axillary compound.

Third, we analysed the absolute length of cycle phases, not change scores, by using log-survivor analysis developed for temporal data ${ }^{5}$. All temporal data are "skewed" and randomly have a Poisson, not a normal, distribution, and extreme values are not "outliers" but part of the temporal distribution. Survivor analysis indicated that axillary compounds change the timing of the preovulatory surge of luteinizing hormone, rather than the onset or duration of menses or the lifespan of the corpus luteum. So we did use a "clearly defined endpoint measured in hours": the timing of the preovulatory surge of luteinizing hormone ${ }^{6}$, and not just the coarser measure of menstrual-cycle length. The concordance of our three independent statistical methods creates a robust foundation for concluding that axillary compounds significantly change the length of the menstrual cycle by altering the follicular phase.

Our log-survivor plot confirmed that the main effect is not driven just by the extreme cases, and their removal does not "negate the claim". Moreover, the extreme 
cases do not contribute as much to the effect as Whitten speculates. We emphasized variation in response so future investigators would not expect all subjects to have the mean response. Our computer model ${ }^{7}$ showed that such individual differences are necessary for the patterns we see in nature. Determining the basis for these differences is an important topic for future research.

Our comparative approach and use of computer modelling do not imply that rats and humans are the same, or the same as computers. They merely suggest that the various forms of social regulation of ovulation in these species can be predicted by conceptualizing their interactions as a system of mutually entrained oscillators. Our corroborated model enabled us to broaden our original focus on synchrony, which is only one special case, to fundamental phero-monal signals that can change the time of ovulation in various ways.

\section{Martha K. McClintock}

Department of Psychology, University of Chicago, 5730 Woodlawn Avenue, Chicago,

Illinois 60637, USA

e-mailmkm1@midway.uchicago.edu

1. McClintock, M. K. in Reproduction in Context (eds Wallen, K. \& Schneider, J.) (MIT Press, Cambridge, Massachusetts, 1999). 2. McClintock, M. K. Annu. Rev. Sex. Res. 9, 77-95 (1999).

3. Trevathan, W. R., Burleson, M. H. \& Gregory, W. L. Psychoneuroendocrinology 18, 425-435 (1993).

4. Stern, K. \& McClintock, M. K. Nature 392, 177-179 (1998).

5. McClintock, M. K. in Chemical Signals in Vertebrates (eds Müller-Schwarze, D. \& Silverstein, R. M.) 159-178 (Plenum, New York, 1982)

6. Stern, K. \& McClintock, M. K. in Psychopharmacology of Women (eds Jensvold, M. F., Halbreich, U. \& Hamilton, J.) 393-413 (American Psychiatry Press, Washington DC, 1996).

7. Schank, J. \& McClintock, M. K. J. Theor. Biol. 157, 317-362 (1992)

\section{Enterobacteria}

\section{Antibiotic resistance found in wild rodents}

Resistance to antibiotics is an increasingly common problem in both veterinary and human medicine, and its management is the subject of urgent debate ${ }^{1-4}$. Efforts to reduce this resistance are based on the assumption that it is maintained in bacterial populations as a result of exposure to antibiotics, and that restricting the use of antibiotics should therefore restrain the spread of resistance. But we have found that antibiotic resistance is prevalent in populations of wild rodents that have not been exposed to antibiotics, indicating that approaches to control it based on this assumption may be overoptimistic.

The source of antibiotic-resistance genes is not always known. They can evolve within the treated host species ${ }^{5}$ or, frequently, like the genes encoding the antibiotics themselves, as a result of natural inter- and intraspecific bacterial competition ${ }^{3,6,7}$. The

\begin{tabular}{|c|c|c|c|c|c|c|c|}
\hline $\begin{array}{l}\text { Bacteria } \\
\text { (no. of isolates) }\end{array}$ & Te & Tm & $\begin{array}{l}\text { ercentage } \\
\mathrm{Na}\end{array}$ & $\begin{array}{l}\text { resista } \\
\mathrm{Cm}\end{array}$ & $\begin{array}{c}\left(\mathrm{MIC}_{50}: \mathrm{MIC}_{90}\right) \\
\mathrm{Amc}\end{array}$ & Ap & Cxm \\
\hline $\begin{array}{l}\text { Hafnia alvei } \\
\text { (41) }\end{array}$ & $\begin{array}{l}76 \\
(4: 4)\end{array}$ & $\begin{array}{c}10 \\
(0.5: 0.5)\end{array}$ & $\begin{array}{c}24 \\
(1:>64)\end{array}$ & $\begin{array}{c}0 \\
(0.5: 2)\end{array}$ & $\begin{array}{c}98 \\
(>64:>64)\end{array}$ & $\begin{array}{c}95 \\
(>64:>64)\end{array}$ & $\begin{array}{c}100 \\
(64:>64)\end{array}$ \\
\hline $\begin{array}{l}\text { Escherichia coli } \\
\text { (35) }\end{array}$ & $\begin{array}{l}14 \\
(1: 2)\end{array}$ & $\begin{array}{c}0 \\
(0.5: 0.5)\end{array}$ & $\begin{array}{c}9 \\
(1: 1)\end{array}$ & $\begin{array}{c}0 \\
(1: 2)\end{array}$ & $\begin{array}{c}97 \\
(16: 32)\end{array}$ & $\begin{array}{c}89 \\
(16: 64)\end{array}$ & $\begin{array}{c}100 \\
(16:>64)\end{array}$ \\
\hline $\begin{array}{l}\text { Serratia liquefaciens } \\
(30)\end{array}$ & $\begin{array}{l}63 \\
(2:>64)\end{array}$ & $\begin{array}{c}30 \\
(0.5: 32)\end{array}$ & $\begin{array}{c}30 \\
(0.5: 8)\end{array}$ & $\begin{array}{c}0 \\
(2: 4)\end{array}$ & $\begin{array}{c}100 \\
(>64:>64)\end{array}$ & $\begin{array}{l}97 \\
(>64:>64)\end{array}$ & $\begin{array}{c}90 \\
(64:>64)\end{array}$ \\
\hline $\begin{array}{l}\text { Alcaligenes spp. } \\
\text { (18) }\end{array}$ & $\begin{array}{c}44 \\
(1: 2)\end{array}$ & $\begin{array}{c}67 \\
(8:>64)\end{array}$ & $\begin{array}{c}56 \\
(4: 16)\end{array}$ & $\begin{array}{c}0 \\
(1: 4)\end{array}$ & $\begin{array}{c}67 \\
(64:>64)\end{array}$ & $\begin{array}{c}67 \\
(>64:>64)\end{array}$ & $\begin{array}{c}78 \\
(>64:>64)\end{array}$ \\
\hline $\begin{array}{l}\text { Serratia fonticola } \\
\text { (18) }\end{array}$ & $\begin{array}{l}50 \\
(1: 4)\end{array}$ & $\begin{array}{c}0 \\
(0.5: 0.5)\end{array}$ & $\begin{array}{c}22 \\
(0.5:>64)\end{array}$ & $\begin{array}{c}0 \\
(0.5: 1)\end{array}$ & $\begin{array}{c}72 \\
(32:>64)\end{array}$ & $\begin{array}{c}94 \\
(>64:>64)\end{array}$ & $\begin{array}{c}67 \\
(>64:>64)\end{array}$ \\
\hline $\begin{array}{l}\text { Enterobacter intermedius } \\
\text { (13) }\end{array}$ & $\begin{array}{l}39 \\
(1: 2)\end{array}$ & $\begin{array}{c}23 \\
(0.5: 1)\end{array}$ & $\begin{array}{c}23 \\
(1: 8)\end{array}$ & $\begin{array}{c}0 \\
0.5: 1)\end{array}$ & $\begin{array}{c}85 \\
(32:>64)\end{array}$ & $\begin{array}{c}92 \\
(64:>64)\end{array}$ & $(8:>64)$ \\
\hline $\begin{array}{l}\text { Enterobacter amnigenus } \\
\text { (10) }\end{array}$ & $\begin{array}{l}50 \\
(1: 4)\end{array}$ & $\begin{array}{c}0 \\
(0.5: 0.5)\end{array}$ & $\begin{array}{c}40 \\
(1:>64)\end{array}$ & $\begin{array}{c}0 \\
(1: 1)\end{array}$ & $\begin{array}{c}90 \\
(32:>64)\end{array}$ & $\begin{array}{c}100 \\
(>64:>64)\end{array}$ & $\begin{array}{c}90 \\
(>64:>64)\end{array}$ \\
\hline $\begin{array}{l}\text { Cedacae davisiae } \\
\text { (9) }\end{array}$ & $\begin{array}{c}44 \\
(0.5: 4)\end{array}$ & $\begin{array}{c}22 \\
(0.5: 1)\end{array}$ & $\begin{array}{c}22 \\
(0.5:>64)\end{array}$ & $\begin{array}{c}0 \\
(0.5: 1)\end{array}$ & $\begin{array}{c}67 \\
(>64:>64)\end{array}$ & $\begin{array}{c}89 \\
(64:>64)\end{array}$ & $\begin{array}{c}89 \\
(32:>64)\end{array}$ \\
\hline $\begin{array}{l}\text { Providencia rustigianii } \\
\text { (6) }\end{array}$ & $\begin{array}{l}17 \\
(1: 1)\end{array}$ & $\begin{array}{c}17 \\
(0.5: 0.5)\end{array}$ & $\begin{array}{c}17 \\
(1: 1)\end{array}$ & $\begin{array}{c}0 \\
(1: 2)\end{array}$ & $\begin{array}{c}100 \\
(32:>64)\end{array}$ & $\begin{array}{c}83 \\
(64:>64)\end{array}$ & $\begin{array}{c}67 \\
(32:>64)\end{array}$ \\
\hline
\end{tabular}

The prevalence of resistance is expressed as the percentage of isolates that are resistant (based on breakpoints). The degree of resistance in the population overall is given by the minimum inhibitory concentration for $50 \%$ and $90 \%$ of isolates $\left(\mathrm{MIC}_{50}\right.$ and $\left.\mathrm{MIC}_{90}\right)$. Antibiotics: Te, tetracycline; Tm, trimethoprim; $\mathrm{Na}$, naladixic acid; $\mathrm{Cm}$, chloramphenicol; Amc, amoxycillin/clavulanic acid; Ap, amoxycillin; Cxm, cefuroxime.

expression of antibiotic resistance in bacteria may also involve a fitness cost that is disadvantageous compared with susceptible bacteria unless antibiotics are present in the environment ${ }^{2,4}$, and resistance would gradually be lost from untreated populations. This idea is supported by some laboratory experiments and by a low prevalence (but, importantly, not absence) of resistance in human and animal populations not exposed to antibiotics ${ }^{8,9}$.

If this is the case then improving the management of antibiotics should reduce the prevalence of resistance. However, compensatory mechanisms can evolve to overcome any small disadvantage of resistance in the absence of antibiotic selection, and resistance can be maintained in populations in the apparent absence of specific antibiotic selection for several years ${ }^{4,10-13}$.

To test whether the development of antibiotic resistance is less prevalent in the absence of exposure to antibiotics, we surveyed resistance in commensal, enteric Enterobacteriaceae isolated from two wild populations of small rodents. Faeces from 38 bank voles (Clethrionomys glareolus) and 70 wood mice (Apodemus sylvaticus) were collected from two woodland sites on the Wirral peninsula in northwest England. The first wood is surrounded by more woodland, gardens and an ornamental lake; the second wood is surrounded by woods and by meadows in which heifers (but not dairy cows) are occasionally kept. Pheasant feed containing the antibiotic tylosin was sometimes distributed in the second site, but otherwise the rodents had minimal contact with antibiotics or with domestic animals routinely treated with them.

The most abundant enterobacterial isolate from each sample was screened for resistance using minimum inhibitory concentrations (MICs) of seven representative antibiotics $^{14}$, and the prevalence of resistance was calculated for 'breakpoint' MICs to reflect its clinical significance (at least for humans $)^{14}$ (Table 1); only those species isolated six or more times are included, although the patterns were the same for less frequently isolated bacteria.

Overall, $90 \%$ of coliforms were resistant to amoxycillin, amoxycillin/clavulanic acid and cefuroxime. Depending on the bacterial species, $14-76 \%$ of coliforms were tetracycline resistant and 0-67\% were trimethoprim resistant, but all of them were sensitive to chloramphenicol. Controlled disc diffusion was also carried out on six antibiotics (ampicillin, gentamicin, apramycin, sulphonamides, cefotaxime and cephradine). Overall, $90 \%$ were ampicillin resistant, as a result of $\beta$-lactamase expression in more than half the cases (as determined by hydrolysis of a chromogenic cephalosporin, nitrocefin). The level of resistance to apramycin was low, at $12-33 \%$, whereas resistance to the other antibiotics was comparable, at $33-73 \%$.

Our results show that resistance to antibiotics is widespread in at least some wild populations, even though these have never to our knowledge been exposed to antibiotics, and they undermine the presumption that resistance will decline in the absence of antibiotic treatment. The ori$\operatorname{gin}(\mathrm{s})$ of the resistance and the selection mechanisms (if indeed such mechanisms are necessary) responsible for maintaining a high prevalence of resistance are unknown. It is important to address these questions, not least because similar mechanisms may operate in farm animals and humans, in which case the management of antibiotic resistance may need to be reconsidered.

Moira A. Gilliver, Malcolm Bennett, Michael Begon, Sarah M. Hazel, C. Anthony Hart 